\title{
Research Progress of High-Temperature-Resistant Fiber Grating and Application in the Field of Sensing
}

\author{
Dequan Feng ${ }^{1, \text { a }}$, Ruiying Shang ${ }^{2, \text { b }}$, Lu Yang ${ }^{3, c}$ and Xing Zhang ${ }^{4, d}$ \\ 1,2,3,4 College of Science, Xi'an Shiyou University, Xi'an,710065, China

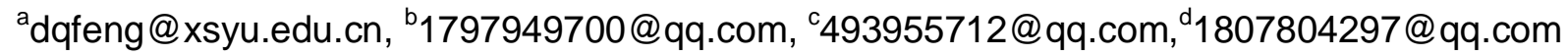

\begin{abstract}
Keywords: Fiber gratings, High temperature, Sensor
Abstract. The application of high-temperature-resistant fiber grating in the field of sensing is introduced in the paper. The basic sensing principle of fiber grating as the sensor is expounded. Fabricating method, high temperature characteristics, advantages and disadvantages of the main high-temperature-resistant fiber are introduced. The application of high-temperature-resistant fiber grating is pointed out and its development prospect is also discussed.
\end{abstract}

\section{Introduction}

As a new type of optical fiber passive device, fiber grating has been widely used in the field of optical fiber sensing since it was born. With the maturity of grating writing technology, the research of fiber grating has been developed greatly. Because of its excellent characteristics such as strong anti-interference, corrosion resistance, small volume, light weight, long service life, no connection loss, achieving multi-point distributed measurement and other excellent characteristics, it can be widely used in the field of optical sensing. In recent years, optical fiber grating sensor working at normal temperature environment has been widely used in aerospace, military equipment, petrochemical industry, electric power system, safety monitoring and other fields, and has made many pioneering achievements [1-3].

However, in the field of high-temperature and extreme environments, such as in metallurgy, oil exploitation, thermal power, nuclear power, space exploration, missile guidance, and the internal combustion engine, engine, turbine and rocket propulsion and other industries, Part of the sensor need to work in a high temperature environment above 300 degrees Celsius, but performance of the ordinary fiber grating resisting high temperature is poor. Working in high temperature environment for a long time, the general grating will gradually decline until be erased completely [4], which greatly limits the application of fiber grating in the field of high temperature. Therefore, the development of stable performance of high-temperature fiber grating has been the hot spot and technical difficulties in the field of application of fiber grating in high-temperature, and research members domestic and abroad have made lots of work in this aspect [5-8]. At present, many improvement schemes have been put forward, such as high temperature regeneration technology, ultrafast laser processing technology, chemical composition of the optical fiber grating (CCG), special ion doped fiber grating etc. The fabrication methods, high temperature properties and advantages and disadvantages of these high temperature resistant fiber gratings were mainly focused on.

\section{Basic sensing principle of fiber Bragg grating:}

For the fiber Bragg grating (FBG), the center reflection wavelength can be expressed by the following formula:

$$
\lambda_{B}=2 n_{\text {eff }} \Lambda
$$

Among them, $\lambda_{B}$ is the central reflection wavelength of FBG, $n_{\text {eff }}$ is the effective refractive index of FBG, and the $\Lambda$ is the period of the grating.

We can see $\lambda_{B}$ changes with $n_{\text {eff }}$ and $\Lambda, n_{\text {eff }}$ and $\Lambda$ are affected by the factors such as strain 
and temperature, thus move the wavelength. Therefore, the change of strain and temperature can be obtained through $\lambda_{B}$ changes, which is the basic sensing principle of FBG.

\section{Fabrication and temperature resistance of high-temperature-resistant fiber grating}

The temperature of so-called high temperature fiber grating, there is no strict boundaries, integrating predecessors' research, with reference to the conventional type I fiber grating simply working under $300^{\circ} \mathrm{C}$, here that can work in the long-term stability above $300^{\circ} \mathrm{C}$, no thermal decay in, no matter what kind of formation of the fiber grating can be called high temperature fiber grating.

The initial fiber grating is a type I fiber grating, which is suitable for the normal temperature environment, and cannot be used for high temperature measurement. Although a common grating it is, it is the most widely used fiber grating. It has an ideal transmission spectrum, but it will gradually degenerate in the high temperature environment, that is, the lower thermal stability, such as the type I fiber gratings written in the common boron and Germanium doped fiber are only suitable for the working environment of below $200^{\circ} \mathrm{C}$. When the temperature is higher than $200^{\circ} \mathrm{C}$, the reflectivity decreases with the increase of the temperature, and the grating can be completely erased in the high temperature environment of $350^{\circ} \mathrm{C}$. S. Baker [4] has proved that I type fiber grating can only be stable below $300^{\circ} \mathrm{C}$. In order to break through the temperature limitation of I fiber grating, people continue to study the formation mechanism of different thermal stability of fiber grating, and thus put forward a number of different high temperature grating, making temperature limitation of fiber grating breakthrough in succession. Mainly include the following:

\section{Type II optical fiber grating}

Type II optical fiber grating is made by exposed high UV exposure, instantaneous local temperature up to thousands of degrees, thus leading to the physical damage of the fiber core by the melting quartz substrate. In the process of preparation, the laser possessing high energy density are required. Currently used for carving II type of fiber grating laser mainly include: excimer laser and high power femtosecond laser. The laser in the preparation process requires high energy density, the laser used for writing type fiber grating are high power excimer laser and femtosecond laser. Archambault [9] using excimer laser with wavelength of $248 \mathrm{~nm}$ and energy of $40 \mathrm{~mJ} / \mathrm{cm} 2$, in the numerical aperture of 0.25 doped germanium (mole fraction is $15 \%$ ) fiber type II grating was fabricated by using the method interference in optical fiber. In this way, after the $24 \mathrm{~h}$ fiber grating was placed at $800^{\circ} \mathrm{C}$, the reflectivity was not significantly reduced; After placing $24 \mathrm{~h}$ at $900^{\circ} \mathrm{C}$ in high temperature environment, the reflectivity is greatly reduced; Under the temperature of $1000^{\circ} \mathrm{C}$ placed $4 \mathrm{~h}$ grating can be completely erased. Martinez [10] used femtosecond laser pulses combined with point by point method to write type II fiber grating on a single mode fiber and found that the grating could work at $1000^{\circ} \mathrm{C}$. Mihailov [11] used femtosecond laser to write a FBG on a common single mode fiber by phase mask plate method. In order to further enhance the high temperature characteristic of type II fiber grating, Grobnic [12] made normal working temperature at $1500^{\circ} \mathrm{C}$ of type II fiber grating successfully, and its highest working temperature up to $2000^{\circ} \mathrm{C}$. However, long time required for production of laser exposure and it is too difficult to mass production.

\section{Type IIA optical fiber grating}

Type IIA fiber grating is made by using two-photon absorption effect of fiber to ultraviolet (UV) laser thus producing negative modulation of refractive index. This kind of fiber grating is of good high-temperature stability, with standing high temperature $500^{\circ} \mathrm{C}$ to $700^{\circ} \mathrm{C}$. Dong [13] using 
boron-germanium doped fiber laser carving on type IIA fiber grating, found that the high the laser energy is, the easier to type IIA fiber grating is prepared [14]. Groothoff [15] by using unstable resonator excimer laser to write type IIA fiber grating, found that the reflectivity and transmittance of the fiber grating at the temperature of $700^{\circ} \mathrm{C}$ were not significantly changed and arise heat attenuation surpass $800^{\circ} \mathrm{C}$. We can see that the thermal stability of type IIA fiber grating is between type I and type II fiber grating, and it can bear the high temperature of $500{ }^{\circ} \mathrm{C} \sim 700{ }^{\circ} \mathrm{C}$ and production cost is low relatively. But longer production cycle is a disadvantage.

\section{Special doped optical fiber grating}

Special ion doped grating is a kind of fiber grating doped in some special ion [such as tin (Sn4 +), antimony $(\mathrm{Sb} 3+)$, indium $(\operatorname{In} 3+)$, bismuth $(\mathrm{Bi} 3+)$ ], possessing good high-temperature stability. Dong [16] studied and found that grating can withstand the high temperature of 800 by using energy density of about $0.25 \mathrm{~J} / \mathrm{cm} 2 \mathrm{KrF}$ excimer laser, with coherent writing method in $\mathrm{Sn}^{4+}$ - doped photosensitive fiber. Shen [17] used 248nm laser irradiate $\mathrm{Sb}^{3+}$-doped fiber, and this kind of fiber is of superior stability than $\mathrm{sn}^{4+}$ - doped fiber. They also write gratings in indium(In3 +) doped [18] and bismuth $(\mathrm{Bi3}+)$ doped [19] fibers, and the reflectivity of the gratings is over $20 \%$ after annealing at high temperature of $900^{\circ} \mathrm{C}$ for $24 \mathrm{~h}$. In conclusion, the production process is easy and convenient. But production cost is high, the waveform reflectivity is low under high temperature environment.

\section{Thermal regeneration fiber grating}

Thermally regenerated fiber grating is a kind of fiber grating which is grown by high humidity baking. It is a new kind of super high temperature resistant fiber grating, which has the advantages of resisting temperature above $1000^{\circ} \mathrm{C}$, small spectral width, large suppression ratio of side mode and matching with common single mode fiber. Based on these advantages, thermal regenerated fiber gratings have been paid more and more attention by researchers both at home and abroad. However, due to the need for continuous high-temperature treatment, it has congenital defects, such as low heating regeneration rate and low mechanical elasticity. These defects severely limit the practical application of thermally regenerated fiber gratings. In recent years, Zhu Jingjing [20] coming from ZheJiang University, found that optimizing boron and germanium doping concentration can make the thermal regeneration fiber grating reflectivity increased from $20 \%$ to $40 \%$, temperature tolerance of $1000^{\circ} \mathrm{C}$ and temperature sensitivity of $15 \mathrm{pm} /{ }^{\circ} \mathrm{C}$. Wang Yupeng [21] verified the feasibility of heat regeneration of writing in the commercial single-mode fiber chirped fiber by using $248 \mathrm{~nm}$ excimer laser. The experimental results show that the thermally regenerated chirped grating retains the same spectral bandwidth, and maintains a very good spectral property when the temperature reaches $1000^{\circ} \mathrm{C}$. The repeated temperature experiments show that the chirped gratings maintain a very stable and reproducible spectral response in the range of $25^{\circ} \mathrm{C}$ to $1000^{\circ} \mathrm{C}$. To sum up, the highest temperature up to $1000^{\circ} \mathrm{C}$ and the spectral width is small. Thermal regeneration rate is low and fragile. And production process is relatively complex.

\section{Chemical component fiber grating (regenerated fiber grating)}

The chemical composition of fiber grating (CCG) modulation in the refractive index of the fiber core is caused by periodic distribution of chemical components in the core. The process of production including the grating degeneration and regeneration, thus also known as regenerative fiber grating. This kind of grating is of so excellent high temperature stability that work normally at $1000^{\circ} \mathrm{C}[22]$. The production process of chemical composition of fiber grating includes hydrogen loading, UV, the process of hydrogen diffusion and high temperature annealing treatment, in which the grating degeneration and regeneration occurs in the high temperature annealing stage. 
Researchers have produced chemical component fiber grating in erbium-doped[23] and boron-germanium-doped[24-25]fiber and proved that it can work normally at $1295^{\circ} \mathrm{C}$. The higher the content of boron and germanium in the doped fiber, the higher the reflectivity of the chemical component fiber grating. The lower the erasing temperature is, the worse the thermal stability is. Canning [26] of IPL Laboratory, coming from the university of Sydney, reported reduced regenerated fiber grating by using the high temperature annealing method in hydrogen loaded fiber. This kind of grating can work stably in temperature above $1100^{\circ} \mathrm{C}$, even the highest up to $1295^{\circ} \mathrm{C}$.Wang Tao [27] produced and studied the high temperature characteristics of the regenerated fiber grating. It is found that the high temperature regeneration and annealing process have a great influence on the temperature response of the grating below 300, and the response to the temperature above $300^{\circ} \mathrm{C}$ is small. The experimental results show that the regenerative grating has good high-temperature-resistant and can work stably at $1000^{\circ} \mathrm{C}$, and the post annealing treatment can further improve the high temperature resistance and is suitable for use as a high-temperature sensor. The chemical composition of fiber grating is of wide belt, good spectral shape, reuse ability strong and the production cost is low. It has low reflectivity and need long annealing time and fiber is very fragile after annealing.

\section{Structural change type long period fiber grating}

In 1996, AT\&T bell laboratories Vengsarkar irradiating hydrogen loaded Silicon germanium fiber by ultraviolet light through amplitude mask, and they produced long period fiber grating (LPFG) for the first time[28]. Then, the domestic and foreign scholars made extensively studied on the production of optical fiber grating, forming a variety of methods, mainly including the preparation method of UV exposure, $\mathrm{CO}_{2}$ laser preparing method, arc discharge method, corrosion groove preparation method, mechanical micro bending preparation method and the way of ion beam system. The above preparation methods have their own advantages and disadvantages. As for high temperature performance, LPFG produced by $\mathrm{CO}_{2}$ laser and arc discharge have high stability of temperature. Davis [29] using $\mathrm{CO}_{2}$ laser pulse inscription in SMF-28 fiber LPFG, the LPFG written in this way can work in the high temperature environment of 1200.Zhang [30] fabricating long period fiber gratings using $800 \mathrm{~nm}$ femtosecond laser. The temperature sensitivity of the grating is $0.056 \mathrm{~nm} / \mathrm{C}$ from 300 to 800 , which is a new type of high temperature testing. LPFG based on above writing methods is of good high temperature stability and withstand the high temperature of 1000, and have higher sensitivity to temperature. In a summary, Structural change type long period fiber grating possessing good high temperature stability, withstanding the high temperature of $1000^{\circ} \mathrm{C}$ and the temperature sensitivity is higher. But it is sensitive to bending and environment refractive index, and used for the temperature sensor need be shielded the influence of these factors.

\section{The application of high temperature resistant fiber grating sensor}

\section{Aerospace engine temperature measurement}

Turbine engines are an important part of locomotives and aerospace vehicles. In order to be able to control the gas turbine engine in the ideal working point of thermodynamics, prevent engine from being damaged due to long time in high temperature condition, we need to monitor the turbine inlet gas temperature. Ordinary temperature control uses thermocouples to measure the gas flow temperature, with the increasing of engine cycle temperature, turbine inlet temperature will exceed the maximum temperature of the thermocouple. when the operating temperature is higher than $1100^{\circ} \mathrm{C}$, the life of thermocouple decreases rapidly. Therefore, when the turbine inlet temperature exceeds this value, it can only measure the inlet temperature of the turbine inlet, and then calculate the inlet temperature according to the empirical formula, it is difficult to achieve accurate 
monitoring of engine temperature. However, the new sensor which can work stably at high temperature can solve this difficult problem.

\section{Temperature measurement in oil and gas well}

Research and development of temperature and pressure sensors which can work in harsh environments such as high temperature, high pressure and corrosion, are of great significance for oil well safety testing. Engineering experience shows that the oil temperature increased every $18^{\circ} \mathrm{C}$, the failure rate of electronic products will increase by 1 time, and military grade electronic components can only be used for oil wells below the temperature of $125^{\circ} \mathrm{C}$. In addition, with the continuous exploitation of oil, oil and gas well depth increasing, the down-hole pressure and temperature also increasing, wells of oil and gas resources exploration and exploitation of the temperature often exceeds this limit, such as heavy oil wells mining temperature above $300^{\circ} \mathrm{C}$. High temperature resistant fiber grating sensor have lots of advantages, such as the measurement signal is not affected by fiber bending loss, transmission distance, resistance to corrosion, large measuring range, measuring in $350^{\circ} \mathrm{C}$, which are very suitable for oil exploration, measurement, mining, transportation applications. That is a convenient and efficient solution to this problem.

\section{Conclusions}

Through summarizing manufacturing methods of several high temperature resistant fiber gratings, high temperature performance overview of research progress, the development of high temperature resistant performance of fiber grating and the latest application of high temperature sensors were concluded. The results show that the high temperature fiber grating is of excellent high-temperature sensing characteristics, especially suitable for measuring high temperature. Through functional packaging, it can work in many harsh environments. In the future, low cost and high temperature resistant fiber gratings and the sensors which can be used in various extreme environments will have broad application prospects. With the development and improvement of all kinds of high temperature fiber gratings, the high temperature fiber grating sensors will be further developed, so as to promote the research work in many high temperature fields.

\section{Acknowledgements}

This research was supported in part by National Undergraduate Training Program for Innovation and Entrepreneurship Grant 201510705251, in part by the Shaanxi province Education department natural Science under Grant 12JK0683 and 13JS088.

\section{References}

[1]Hao Sun, Manli Hu, Qiangzhou Rong, et al. Optics Communications 323 (2014) 28-31(In Chinese)

[2]Fei Fan, Da Li, Weiyu Wang, et al. North China Earthquake Sciences, 2015,33(S):48-51(In Chinese)

[3]Guangrui Lu. Petrochemical Industry Technology, 2016, 7. (In Chinese)

[4]S. R. Baker, H.N. Rourke, V. Baker et al. Lightwave Technology, 1997, 15(8):1470-1477.

[5]S.Bandyopadhyay, J.Canning, P.Biswas et al. Optical Society of America, 2010, 19.

[6]Yupeng Wang. Ultra high temperature sensing based on thermally regenerated fiber Bragg grating [D]. Xi'an: Northwestern University, 2015. (In Chinese)

[7]Zhou Zhang, Wenge Yu. Instrument Technique and Sensor, 2014(09) (In Chinese)

[8]Hantao Li, Xiaoyan Sun, Xinran Dong. Optoelectronic lasers.2014 (10) (In Chinese)

[9]J.L.Archambault, L.Reekie, P. St.J.Russell. Electron Lett , 1993, 29(5):453-455 
[10]A. Martinez, I. Y. Khrushchev, I. Bennion. Electron. Lett. , 2005, 41(4): 224-225

[11]S. J. Mihailov, C.W. Smelser, D. Grobnic et al. J. Lightwave Technol., 2004, 22(1): 94-100

[12]D. Grobnic, S. J. Mihailov, C. W. Smelser et al. IEEE photon. Technol. Lett. , 2004, 16(11): 2505-2507

[13]L. Dong, W. F. Liu, L. Reekie. Opt. Lett. , 1996, 21(24): 2032-2034

[14]Niay, P. Bernage, S. Legoubin et al. Opt. Commun. , 1994, 113(1-3):176-192

[15]N. Groothoff, J. Canning. Opt. Lett. , 2004, 29(20): 2360-2362

[16]L. Dong, J. L. Cruz, L. Reekie et al. IEEE Photon. Technol. Lett. , 1995, 7(9): 1048-1050

[17]Y. H. Shen, J. L. He, T. Sun et al. Opt. Lett. , 2004, 29(6): 554-556

[18]Y. H. Shen, J. Xia, T. Sun et al. IEEE Photon. Technol. Lett., 2004, 16(5): 1319-1321

[19]Y. H. Shen, J. L. He, Y. Q. Qi et al. J. Opt. Soc. Am. B, 2007, 24(3): 430-438

[20]Zhang A. R, Zhou B., et al. Optics Communications, 2011, 284(12):2808-2811.

[21]Yupeng Wang. Ultra high temperature sensing based on thermally regenerated fiber Bragg grating [D]. Xi'an: Northwestern University, 2015:46-51(In Chinese)

[22]Fokine M . OPTICS LETTERS.2002, 27(12): 1016-1018 .

[23]S. Trpkovsski, D. J. Kitcher, G. W. Baxter et al. Opt. Lett. , 2005, 30(6): 607-609

[24 J. J. Zhu, A.P. Zhang, B. Zhou et al. Opt. common., 2011,284(12):2808-2811

[25]Jingjing Zhu, Yurong Jiang, Xue Wei. Trans. Beijing Inst.Technol. 2011, 31(1):83-86(In Chinese)

[26] S. Bandyopadhyay, J. Canning, M. Stevenson, et al. Optics Letter, 2008, 33(16): 1917-1919.

[27]Tao Wang, Dawei He, Yongsheng Wang. Research on fabrication and property of high temperature regenerated grating [D]. Beijing: University of Beijing Jiaotong, 2013. (In Chinese)

[28] A. M. Vengsarkar, P. J. Lemaire, J. B. Judkins, et al. J. Lightwave Technol., 1996, 14(1): 58-65

[29] D. D. Davis, T. K. Gaylord, E. N. Glytsis et al. Electron Lett. , 1999, 35(09): 740-742

[30] Fei Miao, Ling Zhang, Dejun Feng. Optics and precision engineering.2012 (4) (In Chinese) 